\title{
Freshman African engineering student perceptions on academic feedback - A case study from Digital Systems 1
}

\section{Kuriakose, Rangith Baby}

Electrical Electronics and Computer systems, Central University of Technology, South Africa

\begin{abstract}
Providing effective and quality feedback to students in higher education has been identified as an integral part of quality teaching by many researchers in the field of education. However, student perceptions vary drastically as to what they perceive academic feedback to really be. Therefore, this paper aims to present freshman engineering student perceptions of academic feedback from an African perspective. The reason for targeting this group is due to their high dropout rate in higher education in South Africa (around $60 \%$ ). Quantitative data was collected from freshman engineering students enrolled for a module termed Digital Systems 1 at the Central University of Technology in South Africa. A questionnaire was used as the main data collection instrument featuring 21 close ended questions. The results presented in this paper indicate that almost two-thirds (65\%) of the respondents believe that a "grade" written on a test script does not constitute academic feedback. The majority of the respondents (76\%) expect some kind of academic feedback regarding their work, either in writing or orally from their lecturer. A good majority (86\%) of students perceived that getting written comments on their assessments would encourage them to approach the lecturer to seek further clarification. A key recommendation of this study is to find a mechanism or technique of providing constructive feedback to all enrolled students, even in large classes. This needs to be done from the outset of the module in order to reduce the current high dropout rates among freshman engineering students.
\end{abstract}

Keywords: constructive feedback; freshman drop-out rates; learning cycle; student perceptions 


\section{Introduction}

"Education is the most powerful weapon which you can use to change the world" ("Mandela"). These are the famous words of a late president of South Africa (SA), Nelson Mandela. Unfortunately, the call to education has not been taken seriously among many youths in SA. Statistics from studies conducted in tertiary educational institutions show (ECNA, 2015; J swart, 2014; John, 2013) that up to 60\% of students dropout in their freshman year. They further state that of the rest that make it into their second year, only $35 \%$ graduate in the allotted time of the qualification. Reasons for this dropout vary from student to student and from university to university.

The high dropout rate among freshman engineering students at the Central University of Technology (CUT) ("Central University of Technology,"), is due to the high student volume, poor academic background, poor motivation of students and poor preparation for examinations as per previous research(RB Kuriakose, 2014). While the first two reasons are to an extent inherent, the last two reasons may be due to a lack of effective communication between students and faculty.

Academic feedback can be seen as an ideal way of carrying out effective communication between students and faculty (Dowden et al, 2013). Previous research, in the field of economics and finance, shows that students are constructively affected when they receive prompt and constructive feedback (Rowe \& Wood, 2008). Feedback is also closely linked with student retention and progression (Bloxham \& West, 2004; Yorke, 2014). However, there is also research that suggests that feedback is often not read at all or not even understood by students (Brown, 2001). In some instances, students have shown dissatisfaction with the adequacy of feedback (Krause et al 2005). The research question therefore arises "What are student perceptions of academic feedback and are they receiving it with their assessments"?

The aim of this paper is to present the perceptions of freshman engineering students with regard to academic feedback. The hypothesis is that these perceptions will shed light on why students tend to dropout in their freshman year and enable faculty to setup certain interventions to help mitigate this concern. The paper firstly considers what constitutes feedback in academia and then follows with its importance in the learning cycle. Secondly, the research methodology, results and discussions are provided 


\section{Feedback in an academic context}

Feedback, in very simple terms, is a consequence of performance (Hattie, \& Timperley, 2007). It can be conceptualized as information provided by an agent with the aim of improving or enlightening the recipient (Hattie et al., 2007). In an academic context, feedback is often related, to but not restricted to, assessments.

Assessment of student learning can be defined as the systematic collection of information about student learning, using the time, knowledge, expertise, and resources available (Walvoord, 2010). Its purpose is to justify to students how their grade was obtained, as well as to reward specific qualities and recommend aspects that need improvement (UNSW Australia, 2010). Effective feedback is characterized by the following: (Race, 2005);

- It must be timely - Ideally, feedback should be received within a day or two.

- It needs to be intimate and individual - Feedback needs to fit each student's achievement, individual nature and personality.

- It should be empowering - Feedback must be constructive in most instances, strengthening and consolidating learning.

- It must be precise - Feedback must be used to improve the performance of the student, hence one worded feedback like 'weak', 'poor' or even 'excellent' should be avoided. As a result the feedback should be precise as what is right and what needs to be improved.

- It needs to be manageable - Feedback should be such that it is manageable to both lecturers and students. Designing and delivering feedback is a very tedious process, especially if it's a large class. Similarly, too much or too little feedback to students can result in reducing their opportunity to benefit from the feedback and in improving their learning.

There are different types of strategies that can be used to provide effective feedback to students. For the purposes of this research, two common feedback strategies are compared and contrasted. They are (Race, 2005);

- Written feedback: used to give feedback to students on reports, essays and mathematical calculations. Usually needs to be short and concise.

- Oral feedback: used to give face-to-face feedback to students on any work done relating to the module.

Each of these feedback strategies has its own advantages and disadvantages (Race, 2005). The major advantage of written feedback is that students can refer to it again and continue the learning process, while the disadvantage is that it is time consuming for the provider (see Table 1). 
Oral feedback, on the other hand, can be seen as a more personal approach, as students may feel that the lecturer is 'looking out' for them. Unfortunately, this is also a disadvantage as some students might feel threatened by a personal approach and often forget the message. Table 2 describes in detail more advantages and disadvantages of oral feedback.

Table 1.Advantages and disadvantages of written feedback

\begin{tabular}{|l|l|}
\hline Advantages & Disadvantages \\
\hline $\begin{array}{l}\text { Feedback can be personal, } \\
\text { individual, and directly related to the } \\
\text { particular piece of work. }\end{array}$ & $\begin{array}{l}\text { Handwritten feedback can be hard to } \\
\text { read }\end{array}$ \\
\hline $\begin{array}{l}\text { Feedback may be regarded as } \\
\text { authoritative and credible. }\end{array}$ & $\begin{array}{l}\text { When critical, handwritten feedback } \\
\text { - because of its authoritativeness - } \\
\text { can be threatening. }\end{array}$ \\
\hline $\begin{array}{l}\text { The feedback can be tailored to } \\
\text { justify an accompanying assessment }\end{array}$ & $\begin{array}{l}\text { It is slow and time-consuming to } \\
\text { write individually on (or about) } \\
\text { students' work, especially in large } \\
\text { classes. }\end{array}$ \\
\hline $\begin{array}{l}\text { Students can refer to the feedback } \\
\text { again and again, and continue to } \\
\text { learn from it. }\end{array}$ & $\begin{array}{l}\text { Cannot refer to the feedback given to } \\
\text { the students unless one keeps } \\
\text { photocopies of their work with the } \\
\text { comments. }\end{array}$ \\
\hline $\begin{array}{l}\text { Such feedback provides useful } \\
\text { evidence for external scrutiny }\end{array}$ & $\begin{array}{l}\text { It becomes too tempting to } \\
\text { degenerate into shorthand - ticks and } \\
\text { crosses - rather than to express } \\
\text { constructive and critical comments. }\end{array}$ \\
\hline
\end{tabular}


Table 2.Advantages and disadvantages of oral feedback

\begin{tabular}{|l|l|}
\hline Advantages & Disadvantages \\
\hline $\begin{array}{l}\text { Feedback is likely to be found to be } \\
\text { personal, intimate and authoritative. }\end{array}$ & $\begin{array}{l}\text { One-to-one feedback can be } \\
\text { extremely threatening when critical. }\end{array}$ \\
\hline $\begin{array}{l}\text { Can address each individual student's } \\
\text { needs, strengths and weaknesses. }\end{array}$ & $\begin{array}{l}\text { Students can be embarrassed when } \\
\text { receiving constructive feedback and } \\
\text { this can cause them not to fully } \\
\text { benefit from praise. }\end{array}$ \\
\hline $\begin{array}{l}\text { Often much quicker to talk rather } \\
\text { than write or type. }\end{array}$ & $\begin{array}{l}\text { It takes a great deal of time to } \\
\text { organize individual appointments } \\
\text { with each member of large classes. }\end{array}$ \\
\hline $\begin{array}{l}\text { Students might feel at ease to } \\
\text { approach lecturer in future with } \\
\text { problems or queries. }\end{array}$ & $\begin{array}{l}\text { It becomes impossible to remember } \\
\text { exactly what the lecturer said to } \\
\text { whom, when class sizes are large. }\end{array}$ \\
\hline
\end{tabular}

\section{Importance of constructive feedback in learning cycle}

Based on the feedback strategies discussed in the last section, feedback can be further classified as being constructive (or positive) feedback and critical (or negative) feedback. Critical feedback is usually not well-received and makes people defensive (Race, 2005) especially if it is provided in an unskilled manner (The University of Nottingham, 2012). On the other hand, constructive feedback increases self-awareness, offers guidance and encourages development (Hamid \& Mahmood, 2010). Constructive feedback is an important factor in learning. It differs from feedback in that it has the ability to enhance learning in three significant ways (Hounsell, 2007). This is by;

- Accelerating learning: speeding up what can be learned by the students within a given period of time and so enabling learning to take place more rapidly, or in greater depth or scope.

- Optimizing the quality of what is learned: helping to ensure that the learning outcomes achieved and evinced by the students meet the standards hoped for or required.

- Raising individual and collective attainment: enabling students to attain standards or levels of achievement higher than those which they might otherwise have reached.

The importance of constructive feedback in learning is highlighted in Kolb's experiential learning theory (Kolb, Boyatzis, \& Mainemelis, 2000). It is illustrated as a cycle shown in Figure 1. An application of the learning cycle with reference to assessments in a classroom 
follows figure 1 which shows the impact that constructive feedback can have on the learning process.

Each of these stages can be linked to students engaging with assessments. Concrete experience to the student may refer to the experience of completing the assessment. It can be formative or summative. Reflective observation may refer to the constructive feedback provided by the lecturer in reference to the performance in the assessment which concluded as the concrete experience. The abstract conceptualization may refer to the time the student uses to understand the constructive feedback, processing ideas and integrating them into logical theories. The final stage is that of active experimentation, where the student uses the theories that were conceptualized in the previous stage to improve on either the current assessment or future ones.

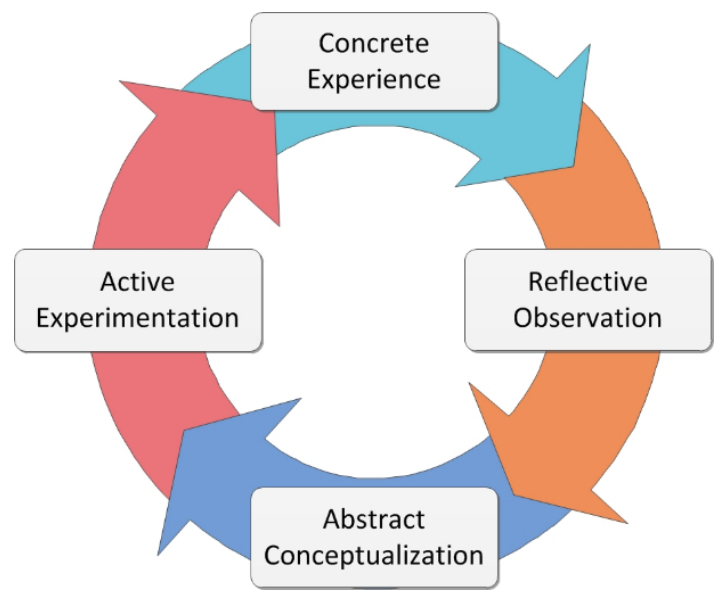

Figure 1: Kolb's learning cycle

Abstract conceptualization is a critical stage where students learn from previous mistakes and creates a path for the coming assessment. This is where constructive feedback is seen as an integral part to learning. It is substantiated by other researchers (Azevedo, R., \& Bernard, 1995)(Bangert-Drowns, R. L., Kulik, C. C., Kulik, J. A., \& Morgan, 1991) who regard constructive feedback as crucial to improving knowledge and skill acquisition. Furthermore, constructive feedback is also seen as a significant factor in motivating student learning (Narciss, 2013).

\section{Research Methodology}

An exploratory study is employed along with descriptive statistics involving quantitative analysis of the collected data. An exploratory design may set the stage for future research and usually involves only a single group of respondents (Jara \& Mellar, 2010). Descriptive 
statistics are used as the results are interpreted with regard to specific freshman engineering students enrolled at CUT. Quantitative analysis is important as it brings a methodical approach to the decision-making process, given that qualitative factors such as "gut feel" may make decisions biased and less than rational (Reddy, W, Higgins, D, Wakefield, 2014).

The target population was restricted to freshman engineering students enrolled for Digital Systems I during 2015 ( $\mathrm{n}=98$ ). An electronic response system (ERS) was used in a classroom environment to obtain student perceptions on specific questions relating to the practical work done in the laboratory. Closed-ended questions, featuring Likert scales, were used based on previous research which focused on student perceptions of practical work done in a laboratory (A. Swart, 2012)(A. J. Swart, 2014). Using this ERS in a classroom environment ensured a high response rate, while the closed-ended questions did not require the participants to express lengthy views. Entering long sentences via the ERS is rather cumbersome and tedious.

The survey was done after the students completed a class test. The results of the study are presented in two sections. The first section shows what students are currently experiencing as feedback in their classroom. The second section shows what they perceive to be good feedback.

\section{Results}

The first question of the survey focused on obtaining student perceptions with regard to what academic feedback they have received thus far at the university. The results showed that $49 \%$ (agreed or strongly agreed) of students felt receiving a mark on a notice board or paper constituted feedback. This is shown in Figure $2.42 \%$ of the students indicated that they had received written comments on their assessment while up to $64 \%$ received oral feedback. These results are shown in Figures 3 and 4.

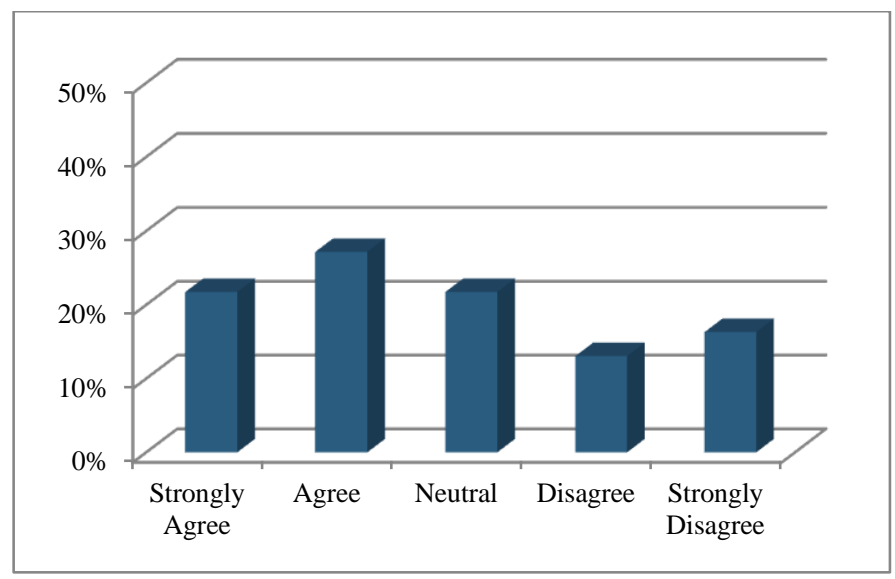


Figure 2: Student response to question if they thought feedback means receiving marks on a notice board or on paper

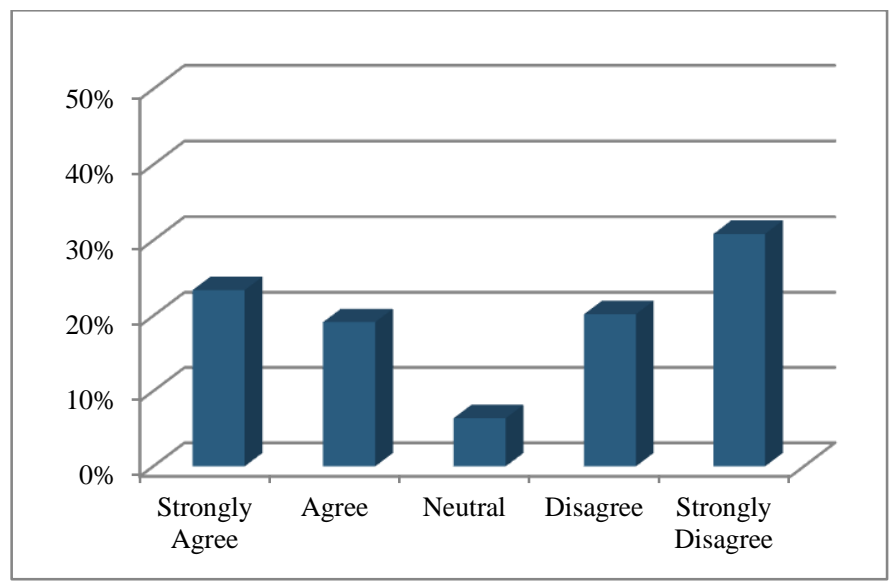

Figure 3: Student response to question if they received written comments on how to improve for the next theory test

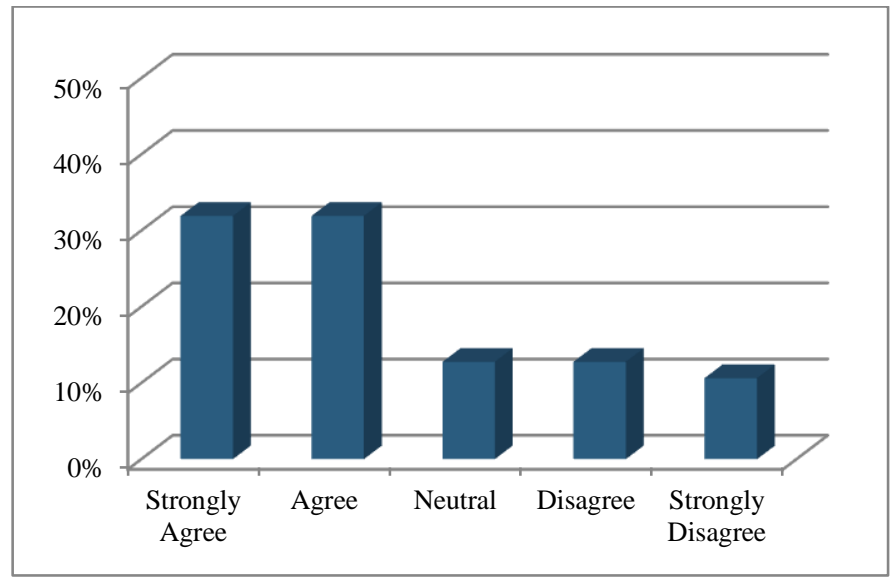

Figure 4: Student response to question if they received oral comments on how to improve for the next theory test

The second section focused on obtaining the perceptions of students towards academic feedback. The first question in this regard tried to ascertain if students felt that it is important for a lecturer to provide constructive feedback on their tests (see Figure 5). 80\% of students agreed (agreed or strongly agreed) that they valued constructive feedback from the lecturer. As a follow up question, they were asked to share their perception on critical feedback from the lecturer. $49 \%$ felt that critical feedback should be given by the lecturer as shown in Figure 6. 


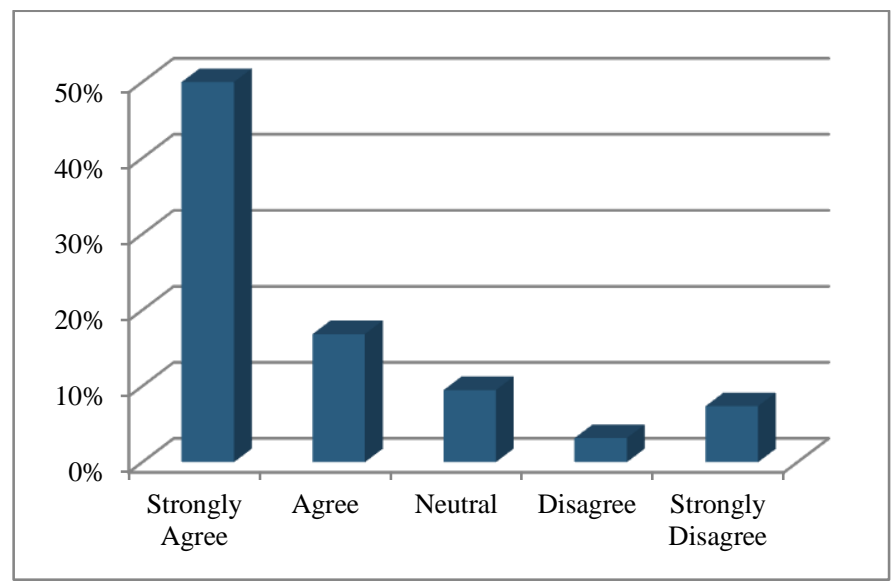

Figure 5: Student response to question if it is important for lecturers to provide constructive feedback

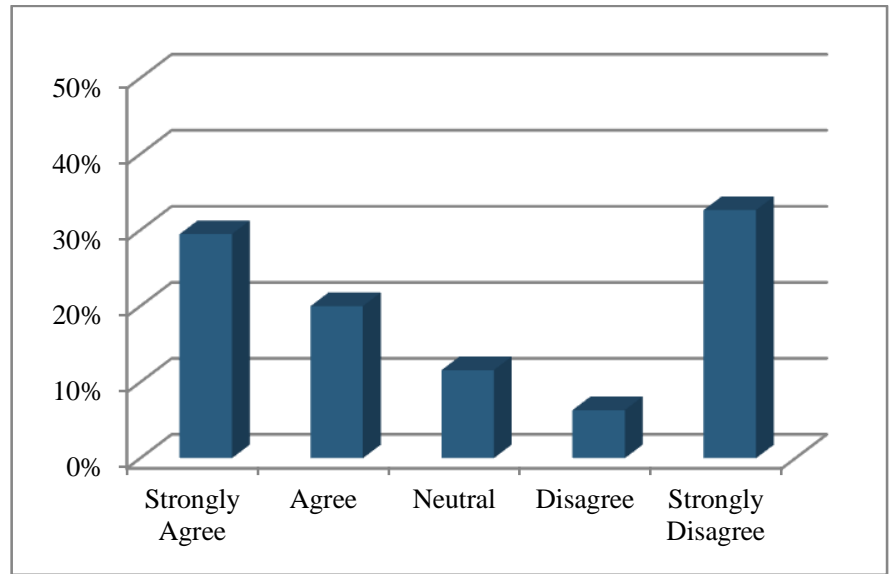

Figure 6: Student response to question if it is important for lecturers to provide critical feedback

\section{Discussions}

Figure 2 revealed that almost half of the class has the perception that a mark on a paper or notice board is what constitutes academic feedback. This misconception may stem from the school environment where a grade may serve to motivate or punish some students and not be an effective communication tool (Jason, 2014). As this survey was associated with freshman engineering students, their answer to this question may be attributed to their short exposure to university life.

The second and third questions, illustrated in Figures 3 and 4, are related to the students' experience of feedback at university. These figures show that students received very little written feedback, while there was considerable oral feedback. While not touting it as an 
excuse, one reason for little written feedback has been attributed to large class sizes (Jin \& Cortazzi, 2013), which is the case in this module.

Students further desire more constructive feedback than critical feedback from their lecturers. This is shown in Figures 5 and 6. They feel with constructive feedback they would be more motivated to improve on future assessments (Burke, 2007). At the same time, Figure 6 shows that only $35 \%$ of the students disagree or strongly disagree to critical feedback. This shows that there is room for the "feedback sandwich" approach identified by Boud and Molly (Chokwe, 2015) which states that negative feedback needs to be sandwiched between two positive comments. Students further felt that written feedback is imperative to their learning. It would help them to engage in self-reflection and enable them to approach the lecturer for further clarity (McGill, 2007).

\section{Conclusions}

The purpose of this paper was to gain insight into the perceptions of freshman engineering students with regard to academic feedback. The results were split into two sections, student perceptions of feedback and their actual experience. The survey was conducted after the students wrote their first class test where a key result indicated that they are not receiving sufficient written feedback. This lack of feedback can result in students repeating mistakes and eventually failing the course or even dropping out of the programme.

The freshman students may not have a had a very clear idea of what academic feedback in a university setting really entails, as they may still relate to feedback from their school days [27]. But they believe that constructive feedback will enable them to reflect on the work they have done and improve on future assessments. They further believe that constructive feedback will bridge the gap between them and their lecturer.

A limitation of this study is that it is restricted to a single semester with the questionnaire administered at the very beginning. A similar survey should be done at the end of the semester to see if there is a variable change in the perception of students. Using a time-lag study may further enhance the results.

A key recommendation in this case would be to find a mechanism or technique of addressing this concern. If this cannot be done for the entire class, then it should be attempted for at least those students who score below $50 \%$ for their first test. This could serve as a necessary intervention to help provide both constructive and critical feedback that has the power to change the educational world of students. 


\section{References}

Azevedo, R., \& Bernard, R. M. (1995). A meta-analysis of the effects of feedback in computer- based instruction. Journal of Educational Computing Research, 13(2), 1995. Retrieved from http://doe.concordia.ca/cslp/Downloads/PDF/CanKnow/Azevedo (1995).pdf

Bangert-Drowns, R. L., Kulik, C. C., Kulik, J. A., \& Morgan, M. (1991). The instructional effects of feedback in test-like events. Review of Educational Research, 61(2), 213-238.

Bloxham, S., \& West, A. (2004). Understanding the rules of the game: marking peer assessment as a medium for developing students' conceptions of assessment. Assessment \& Evaluation in Higher Education, 29(6), 721-733. http://doi.org/10.1080/0260293042000227254

Brown, G. (2001). Assessment: A guide for lecturers. Learning and Teaching Support Network(LTSN) Genesis 3, (3), 1-27.

Burke, B. (2007). Beyond the Grade: Feedback on Student Behavior.

Central University of Technology. (n.d.). Retrieved May 1, 2015, from http://www.cut.ac.za/

Chokwe, J. M. (2015). Students' and tutors' perceptions of feedback on academic essays in an open and distance learning context. Open Praxis, 7(1), 39-56. http://doi.org/10.5944/openpraxis.7.1.154

Dowden, T., Pittaway, S., Yost, H., \& McCarthy, R. (2013). Students' perceptions of written feedback in teacher education: ideally feedback is a continuing two-way communication that encourages progress. Assessment \& Evaluation in Higher Education, 38(3), 349-362. http://doi.org/10.1080/02602938.2011.632676

ECNA. (2015). SA student dropout rate high. Retrieved November 5, 2015, from http://www.enca.com/south-africa/student-dropout-rate-high

Hamid, Y., \& Mahmood, S. (2010). Review Article Understanding constructive feedback: A commitment between teachers and students for academic and professional development Feedback vs Constructive Feedback: Standards of Constructive Feedback: Journal of Pakistan Medical Association, 60(3), 224-227. Retrieved from http://jpma.pakcyber.biz/PdfDownload/1960.pdf

Hattie Helen E-Mail Address, J. T., Hattie, J., \& Timperley, H. (2007). The power of feedback. [References]. Review of Educational Research, .77(1), 16-7. http://doi.org/10.3102/003465430298487

Hounsell, D. (2007). Rethinking assessment in Higher education:Learning for the longer term. (D. Boud \& N. Falchikov, Eds.) (2nd ed.). London and Newyork: Routledge.

Jara, M., \& Mellar, H. (2010). Quality enhancement for e-learning courses: The role of student feedback. Computers and Education, 54(3), 709-714. http://doi.org/10.1016/j.compedu.2009.10.016

Jason, P. (2014). Why Do We Grade? A Look Into Evaluations and Assessments. Retrieved November 1, 2015, from http://www.hotchalkeducationnetwork.com/why-do-we-grade/

J swart, R.B Kuriakose. (2014). Profiles of students registered for work integrated learning at a university of technology over a 16 year period - Are there any concerns? A.J. 
Swart. In International Conference on Education and Information Management,. Durban.

Jin, L., \& Cortazzi, M. (2013). Large Classes, 51(April), 106-116. Retrieved from http://hdl.handle.net/2086/8037

John, V. (2013, May 17). Dropout rate points to lack of support. Mail and Guardian. Johannesburg. Retrieved from http://mg.co.za/article/2013-05-17-dropout-rate-pointsto-lack-of-support

Kolb, D. a, Boyatzis, R. E., \& Mainemelis, C. (2000). Experiential Learning Theory: Previous Research and New Directions. Perspectives on Thinking Learning and Cognitive Styles, 1(216), 227-247. Retrieved from http://www.d.umn.edu/ kgilbert/educ5165-731/Readings/experiential-learningtheory.pdf

Krause, K., Hartley, R., James, R., \& Mcinnis, C. (2005). The First Y Ear Experience in Australian Universities : Findings From a Decade of National Studies.

Mandela, N. (n.d.). Education-brainy qoute. Retrieved November 5, 2015, from http://www.brainyquote.com/quotes/quotes/n/nelsonmand157855.html

McGill, C. Tips for giving students feedback and for encouraging self-reflection and (2007). Retrieved from www.mcgill.ca/files/scsd/Tips_For_Giving_Students_Feedback.pdf

Narciss, S. (2013). Designing and evaluating tutoring feedback strategies for digital learning environments on the basis of the interactive tutoring feedback model. Digital Education Review, 23(1), 7-26.

Race, P. (2005). Using feedback to help students to learn. The Higher Education Academy, (9 octobre 2007), 1-11. Retrieved from http://www.york.ac.uk/admin/aso/learningandteaching/id432_using_feedback.pdf

RB Kuriakose, H. Vermaak. (2014). Using reflective practices to reduce dropout rates among first year students at a University of Technology, a South African perspective. In Frontiers in Education conference.

Reddy, W, Higgins, D,Wakefield, R. (2014). An investigation of property-related decision practice of Australian fund managers. Journal of Property Investment \& Finance, 32, 282-305.

Rowe, A. D., \& Wood, L. N. (2008). Student Perceptions and Preferences for Feedback. Asian Social Science, 4(3), 78-88. http://doi.org/10.5539/ass.v4n3p78

Swart, A. (2012). Enhancing students' perception of single-sideband suppressed-carrier principles by using cooperative and computer-based learning. CAEE, Computer Applications in Engineering Education, 20, 332-338.

Swart, A. J. (2014). Using Problem-Based Learning to Stimulate Entrepreneurial Awareness Among Senior African Undergraduate Students. EURASIA Journal of Mathematics, Science \& Technology Education, 10(2), 125-134. http://doi.org/10.12973/eurasia.2014.1023a

The University of Nottingham. (2012). Personal Development and Performance Review Guide: Prinicples of constructive feedback. 
UNSW Australia. (2010). Giving Assessment Feedback. Retrieved November 9, 2015, from http://www.itl.usyd.edu.au/assessmentresources/pdf/Link8.pdf

Walvoord, B. E. (2010). Assessment Clear and Simple: A Practical Guide for Institutions, Departments, and General Education. (Jossey-Bass, Ed.) (2nd ed.). Wiley and Sons.

Yorke, M. (2014). Formative assessment in higher education : moves towards theory and the enhancement of pedagogic practice. Higher Education, 45(4), 477-501. 